\title{
Experimental study of the effect of non-condensable gases on steam condensation over an inclined tube external surface
}

\author{
Dandan He, Feng Shen, Shengjun Zhang, Xianke Meng, Bin Gao and Likai \\ Fei
}

${ }^{a}$ State Power Investment Corporation Research Institute, Beijing, 102209, China

\begin{abstract}
A new type of passive containment cooling system of nuclear power plant has been put forward in previous research. The effect of non-condensable gases on steam condensation over tube external surface is a key factor to evaluate the heat removal capacity of the system. Experiments of steam condensation over inclined tube external surface under different pressure, wall subcooling and air mass fraction have been carried out. The results show that the steam condensation heat transfer coefficient over inclined tube increases with the decrease of air mass fraction and wall subcooling. The increase of pressure can also enhance the heat transfer coefficient. The inclined tube has a better heat transfer performance than vertical tube's.
\end{abstract}

Keywords: Condensation heat transfer, inclined tube, non-condensable gases, experiment

\section{Introduction}

As the last safety barrier to the escape of radioactive species, the design of containment is essential to ensure the safety of nuclear plant. Under severe accidents, heat released in containment must be removed effectively to guarantee the integrity of containment. Considering improving the long term passive residual heat removal capacity of containment, a time-unlimited passive containment cooling system (TUPAC) has been designed[1]. The system consists of inbuilt heat exchanger, outside air cooler, rising pipe and descending pipe. When accident occurs, steam condensation will happen over the inbuilt heat exchanger and heat the cooling water in tube of exchanger. Natural circulation will then bring the heat outside the containment.

During the process, steam condensation with non-condensable gases over tube external surface will affect the heat removal capacity of the system. Numbers of experimental investigations have been carried out to study this phenomenon. Nusselt[2] first proposed theory about pure steam laminar condensation and obtained a series of theoretical relations. Uchida[3] and Tagami[4] studied steam condensation over vertical plate with non-condensable gases and obtained widely-used relation under normal pressure, but only one parameter was considered. Dehbi [5], Liu [6], Su[7, 8] discussed the effect of non-condensable gases on steam condensation over vertical tube external surface under different pressure and wall subcooling besides air mass fraction. Also they calculated the responding empirical relations under different parameters. In addition, pure steam condensation over inclined tube external surface were studied by Hassan[9], Selin[10], Garrett[11]. The heat transfer coefficient over inclined tube was proved bigger than the value over vertical tube.

In this paper, steam condensation over inclined tube external surface under different pressure, subcooling and air mass fraction are studied and the effect of different parameters on heat transfer coefficient are discussed. The effect of inclination is also researched.

\footnotetext{
* Manuscript received December 16, 2017; revised August 17, 2018.

*Corresponding author. Tel.:+86-186-184-36781; E-mail address: hedandan1 @ snptc.com.cn.

doi: $10.12720 /$ sgce.8.5.539-543
} 


\section{Experimental System and Method}

\subsection{Experimental system}

As shown in Fig. 1, experimental system consists of five parts, including gas injection system, test section, natural circulation loop, forced circulation loop and data acquisition system.

A $4 \mathrm{~m}$ high, $1.5 \mathrm{~m}$ outer diameter carbon steel pressure vessel is used to simulate containment. The design pressure of the vessel is $1 \mathrm{MPa}$. Stainless steel test section located in the middle of the vessel has a $30^{\circ}$ inclination. The effective heat transfer length of test section is $1.8 \mathrm{~m}$ with $38 \mathrm{~mm}$ outer diameter and $2 \mathrm{~mm}$ thickness. The external surface of vessel and horizontal section of test section are all covered by thermal barrier. Steam in vessel is produced by heating deionized water in the bottom water tank. Air is injected into the vessel from air storage tank through upper and bottom inlets. Cooling water in the test section is heated by mixed gases of steam and air, flows into condenser and cooling water tank successively. Water in tank is then pumped back to inlet of vessel and finishes the whole circulation.

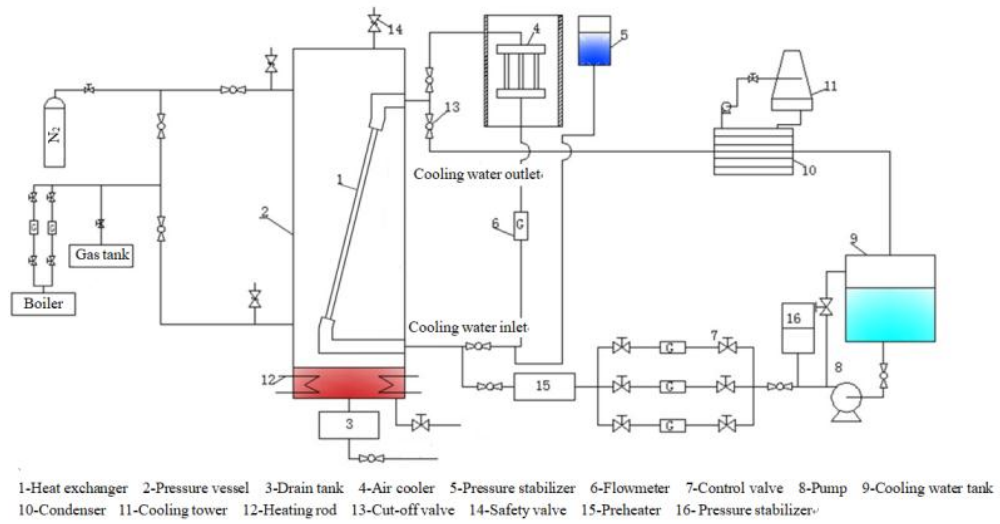

Fig. 1. Experimental system

\subsection{Data acquisition}

In 9 locations at 230 $\mathrm{mm}$ interval along the test section, $18 \mathrm{~K}$-type thermocouples are buried in the opposite side of the outer wall of tube respectively by tin soldering to measure wall temperature. In the same cross section, another $18 \mathrm{~K}$-type thermocouples are fixed $80 \mathrm{~mm}$ away to measure environment temperature in the vessel. Two thermal resistances are installed at the inlet and outlet of test section to measure inlet and outlet temperature of circulation loop. The total pressure of mixed gases is measured by pressure transducer installed in the top of the vessel. Mass flowrate of circulation loop is measured by Coriolis force flowmeter.

Based on NI data acquisition system, voltage and current signal from instrumentations are then transmitted to PC.

\subsection{Measurement method}

Under steady condition, assuming steam saturation and applying the ideal gas law, the total pressure is the sum of air pressure and steam pressure. For the steam pressure, it can be obtained based on environment temperature in vessel and corresponding saturated steam parameters. The ratio of air mass to steam mass and air mass fraction Wa can then be calculated.

$$
\frac{m_{a}}{m_{v}}=\frac{n_{a}}{n_{v}} \cdot \frac{M_{a}}{M_{v}}=\frac{P_{a}}{\mathrm{P}_{v}\left(\overline{\mathrm{T}_{b}}\right)} \cdot \frac{M_{a}}{M_{v}}=\frac{\left(\mathrm{P}-\mathrm{P}_{v}\left(\overline{\mathrm{T}_{b}}\right)\right)}{\mathrm{P}_{v}\left(\overline{\mathrm{T}_{b}}\right)} \cdot \frac{M_{a}}{M_{v}}
$$

Where, m-mass(kg), n-number of molecules(mol), M-molecular weight, P-total pressure(Pa), a-air, vvapor. 


$$
w_{a}=\frac{m_{a}}{m_{a}+m_{v}}
$$

Assuming no energy loss, the heat transfer rate of mixed gases over the tube is equal to the cooling water heat transfer rate which is determined by cooling water temperature change and mass flow rate in the test section.

$$
Q=h A\left(\mathrm{~T}_{b}-\mathrm{T}_{w}\right)=m\left(\mathrm{i}_{\text {out }}-\mathrm{i}_{\text {in }}\right)
$$

Where, h-heat transfer coefficient $\left(\mathrm{W} / \mathrm{m}^{2} .{ }^{\circ} \mathrm{C}\right)$, A-heat transfer area $\left(\mathrm{m}^{2}\right), \quad \mathrm{T}_{\mathrm{b}}$-environment temperature $\left({ }^{\circ} \mathrm{C}\right), \mathrm{T}_{\mathrm{w}}$-wall temperature $\left({ }^{\circ} \mathrm{C}\right)$, m-mass flowrate of cooling water $(\mathrm{kg} / \mathrm{s})$, i-enthalpy of cooling water $(\mathrm{kJ} / \mathrm{kg})$.

The wall temperature and environment temperature in vessel as well as cooling water temperature can be measured by thermocouples. The enthalpy of cooling water can be obtained from steam properties table. Also the flowrate of cooling water is measured by flowmeter. Therefore, the average heat transfer coefficient can be derived by following formula.

$$
\bar{h}=\frac{m\left(\mathrm{i}_{\text {out }}-\mathrm{i}_{\text {in }}\right)}{A\left(\overline{T_{b}}-\overline{T_{w}}\right)}
$$

Where, $\overline{\mathrm{h}}$-average heat transfer coefficient $\left(\mathrm{W} / \mathrm{m}^{2} \cdot{ }^{\circ} \mathrm{C}\right), \overline{\mathrm{T}}$-average temperature $\left({ }^{\circ} \mathrm{C}\right)$.

In this experiment, considering the uncertainty of each measured parameter, an average uncertainty of $15.75 \%$ is obtained based on calculations of measurement error of all instrumentations.

\section{Experimental Results and Discussion}

During experiment, the change of pressure, wall subcooling and air mass fraction can all have influence on the heat transfer over inclined tube. Hence, by controlling two of three variables and adjusting the last one, each parameter can be evaluated.

To study the effect of wall subcooling on heat transfer coefficient, pressure and air mass fraction remain stable, inlet and outlet temperature of test section can be adjusted by changing flowrate of cooling water. As shown in Fig. 2, there is a significant drop of heat transfer over inclined tube with the subcooling increasing. Under a 0.5 air mass fraction, when the wall subcooling increases from $9^{\circ} \mathrm{C}$ to $20^{\circ} \mathrm{C}$, the corresponding heat transfer coefficient decreases about $35 \%$. Since the subcooling is the difference between wall temperature and environment temperature, increase of subcooling means a lower wall temperature. Therefore, the heat transfer is less.

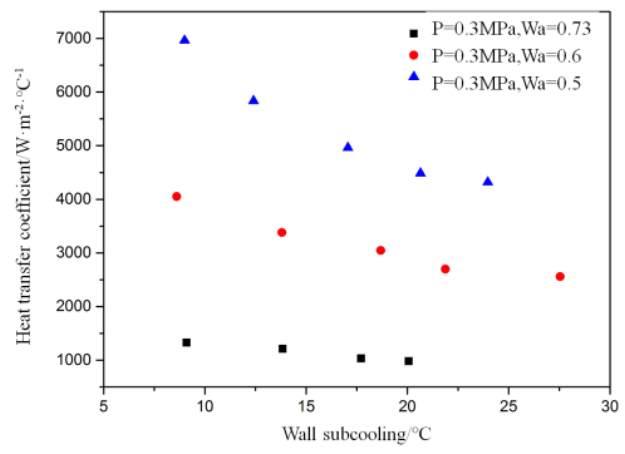

Fig. 2. The effect of wall subcooling. 
In Fig. 2, the effect of wall subcooling on heat transfer coefficient under low air mass fraction is more obvious than the condition of higher air mass fraction. Under a 0.73 air mass fraction, when the wall subcooling increases from $9{ }^{\circ} \mathrm{C}$ to $20^{\circ} \mathrm{C}$, the corresponding heat transfer coefficient decreases about $26 \%$ which has a great difference with $35 \%$.

As shown in Fig. 3, under same pressure, when the wall subcooling stays approximately constant, the heat transfer over inclined tube decreases significantly as the air mass fraction increases. When the pressure of mixed gases is up to $0.3 \mathrm{MPa}$, there is a $15 \%$ decrease of heat transfer with about $5 \%$ increase of air mass fraction. When wall condensation occurs, non-condensable gases in the vessel accumulate at the gas-liquid interface of tube external surface which increases the thermal resistance of diffusion boundary layer and impedes the heat transfer of steam. The heat transfer coefficient of mixed gases decreases a lot compared to pure steam.

By comparison of heat transfer coefficient under different pressure in Fig. 3, increasing pressure can strengthen the heat transfer over inclined tube. Under a 0.5 air mass fraction, when pressure of mixed gases increases from $0.23 \mathrm{MPa}$ to $0.3 \mathrm{MPa}$, the heat transfer coefficient increases about $12 \%$. When the amount of air in vessel is constant, increase of pressure is achieved by heating deionized water which leads to an increase of the amount of steam. Consequently, air mass fraction decreases and steam heat transfer over test section is improved. Heat transfer coefficient increases finally.

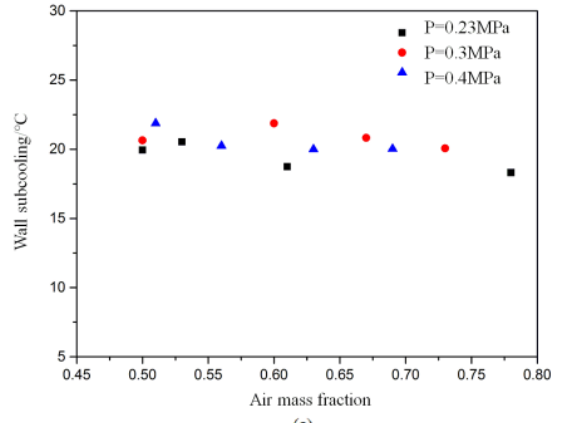

(a)

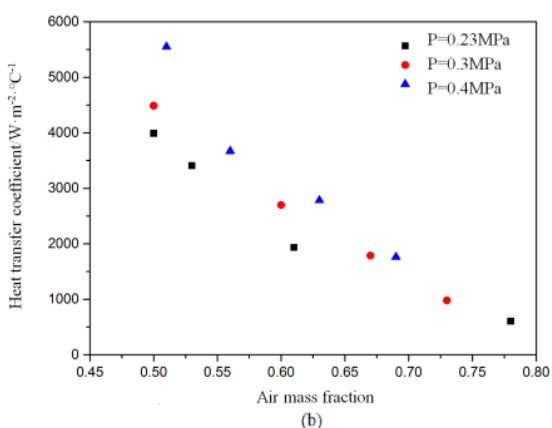

(b)

Fig. 3. Steam condensation heat transfer coefficient curve of pressure and air mass fraction (a) Wall subcooling against air mass fraction (b) Heat transfer coefficient against air mass fraction.

A vertical tube and an inclined tube are mounted in the same location in the vessel successively to study the effect of inclination on the heat transfer coefficient. As shown in Fig. 4, by comparing data under same thermal condition of two test sections, heat transfer coefficient of mixed gases over inclined tube is much bigger than the value of vertical tube which is the same with the condition for pure steam [11]. During the condensation process of mixed gases over inclined tube, a layer of water film forms. The thickness of water film decreases due to gravity as the inclination increases. Decrease of thermal resistance results in the increase of heat transfer coefficient.

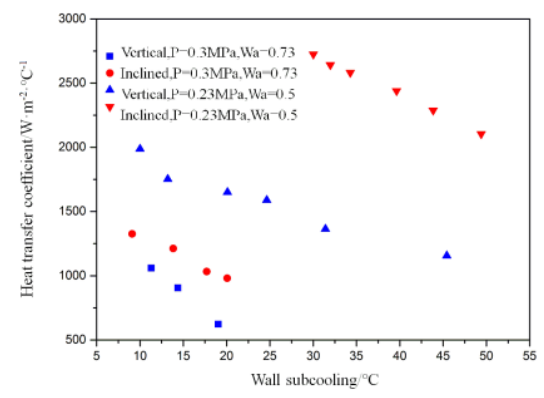

Fig. 4. The effect of inclination. 


\section{Conclusions}

Experiments about steam condensation over inclined tube under different pressure, wall subcooling and air mass fraction have been performed. The following conclusions are made based on experiment:

- Heat transfer coefficient over inclined tube external surface decreases as the wall subcooling and air mass fraction increase. It can also be improved by increasing pressure of mixed gases.

- The effect of wall subcooling on heat transfer coefficient over inclined tube is more significant under low air mass fraction.

- Under the same condition, heat transfer over inclined tube is strengthened compared to vertical tube.

\section{Acknowledgements}

I would like to show my deepest gratitude to all the people who helped me to finish this paper.

\section{References}

[1] Shen F, Zhang S, The theoretical analysis for ultimate passive containment cooling system of nuclear power plant. The 14th National Academic Conference on Reactor Thermal Fluid, 2015, Beijing

[2] Nusselt W, 1916 Dia oberflachen condensation des wasserdampfes Zeitchrift des Vereines deustcher Ingenieure, 60 541-6 569-75

[3] Uchida H, Oyama A, Togo Y, Evaluation of post-incident cooling systems of light water power reactors. Proceedings of Third International Conference on the Peaceful Uses of Atomic Energy. Geneva, 1964.

[4] Tagami T. Interim report on safety assessments and facilities establishment project for June 1965 No. 1 Japanese Atomic Energy Research Agency, 1965.

[5] Dehbi AA. The Effects of Noncondensable Gases on Steam Condensation under Turbulent Natural Convection Conditions. Massachusetts Institute of Technology, 1991.

[6] Liu H, Todreas N, Driscoll M. An experimental investigation of a passive cooling unit for nuclear plant containment nuclear engineering and design. 199: 243-55, 2000.

[7] Su J, Sun Z, Fan G, Ding M. Experimental study of the effect of non-condensable gases on steam condensation over a vertical tube external surface Nuclear Engineering and Design. 262. 201-8, 2013.

[8] Su J, Sun Z, Ding M, Fan G. Analysis of experiments for the effect of noncondensable gases on steam condensation over a vertical tube external surface under low wall subcooling Nuclear Engineering and Design. 278, 2014: 644-50

[9] Hassan KE. Laminar film condensation of pure saturated vapors on inclined circular cylinders A.S.M.E 57-A-35, 1955.

[10] Selin G. Heat transfer by condensing pure vapors outside inclined tubes. Inter. Developments in Heat Transfer, $1963 \mathrm{New}$ York. American Society of Mechanical Engineers, 279-289

[11] Garrett T, Wighton J. The effect of inclination on the heat-transfer coefficients for film condensation of steam on an inclined cylinder International Journal of Heat and Mass Transfer 7, 1964:1235-43. 